International Journal of Biology, Pharmacy and Allied Seiences (IJBPAS)

'A Bridge Betueen Caboratory and QRendo'

WwW.iibpas.com

\title{
GOSSYPIN ANALOGUES PROMISE GOOD RANGE OF DRUGS FOR THE TREATMENT OF EPILEPSY
}

\author{
JAKHMOLA-MANI $\mathbf{R}^{\mathbf{1}^{*}}$, NAGPAL $\mathrm{D}^{\mathbf{2}}$, JAIN A ${ }^{\mathbf{1}}$, CHANDRA $\mathrm{S}^{1}$ AND KATARE DP ${ }^{1}$ \\ ${ }^{1}$ Proteomics and Translational Research Lab, Centre for Medical Biotechnology, Amity \\ Institute of Biotechnology, Amity University, Noida, India, 201313 \\ ${ }^{2}$ Amity Institute of Pharmacy, Amity University, Noida, Uttar Pradesh, 201313 \\ *Corresponding Author: E Mail: dpkatare@amity.edu
}

Received 26 ${ }^{\text {th }}$ Aug. 2019: Revised $17^{\text {th }}$ Sent. 2019: Accented $11^{\text {th }}$ Oct. 2019: Available online $1^{\text {st }}$ Feb. 2020 https://doi.org/10.31032/IJBPAS/2020/9.2.4955

\section{ABSTRACT}

Epilepsy is the disorder of Central Nervous system (CNS) and is characterized by abnormal hyper excitation and hyper synchronization of cortical neurons and currently affecting around 50 million people worldwide. The anti-epileptic drugs (AED) present to-date have serious side effects therefore the approach of the current study is to find the synthetic analogues of gossypin that have same therapeutic effect as gossypin and overcomes the challenges of crossing BBB. Best 20 analogues of gossypin were chosen and screened for the BBB permeability. Docking studies were performed on GABAA receptor and AMPA receptors with $7 \mathrm{BBB}+$ analogues of gossypin along with gossypin itself and 4 FDA approved antiepileptic drugs. Four analogues, PubChem CID (90058541,89888477,89869617,89869564) exhibited very good efficacy in terms of BBB crossing and binding to receptors involved in epilepsy. Their docking energies were better than the marketed drugs. These analogues can be used for future drug development after preclinical studies.

Keywords: Gossypin analogues, Epilepsy, Bioinformatics, BBB, Anti-epileptic drugs (AED) \section{INTRODUCTION}

Gossypin, a bioflavonoid isolated from Hibiscus vitifolius. It is also known as Gossypetin-8-glucoside or Gossypetin 8-Oglucoside. It has been found to have various biological activities like anti- carcinogenic, anti-allergic, anti-diabetic, anti-oxidant to name a few. Gossypin was also found to offer a certain degree of neuroprotection 
and anxiolytic activity as indicated by some studies. Further, it was also found to be a CNS depressant. It has also been demonstrated to have role in the suppression of carcinogenesis, inflammation and angiogenesis [1]. The marketed anti-epileptic drugs have several side effects therefore; researchers are investigating the herbal approach for treatment of epilepsy which also has reduced toxicity as compared to marketed drugs. In one study Gossypin was demonstrated to have anticonvulsant properties [2] and in another it was shown to have neuroprotective effect. The neuroprotective action of gossypin is due to the significant decrease in lipid peroxidation and increase in the level of antioxidant machinery i.e. superoxide dismutase, catalase, glutathione and total thiol $[3,4]$. This study suggested that direct free radical scavenging activity is accountable for the antioxidant and neuroprotective property of gossypin. Similarly, gossypin was shown to inhibits the neuronal damage caused by ROS and contribute to its neuroprotective actions [5]. All researches thus gave the positive suggestion that gossypin may prove to be a safer and natural alternative to treat epilepsy.

Recently we reported for the first time, beneficial effects of liposomal gossypin formulation in animal models of epilepsy
[6]. In the current study we have explored synthetic analogues of gossypin and screened them to check their see if they can be fit for use as a drug in future.

\section{METHODS}

Retrieval of protein receptors, gossypin analogues and screening of gossypin analogues for Blood Brain Barrier (BBB) Permeability

Structure of AMPA and GABAA receptor was retrieved from Protein Data Bank (PDB). The PDB ID for AMPA and GABAA receptor (GABA receptor subunit $\beta-3)$ is $3 \mathrm{UA} 8$ and $4 \mathrm{COF}$ respectively. Active analogues of Gossypin were screened using PubChem Structure Search tool [7]

(https://pubchem.ncbi.nlm.nih.gov/search/s earch.cgi\#) at $>95 \%$ similarity and applying filter of MW 400-480 g/mol. PubChem Structure Search tool allows PubChem Compound database to be queried by chemical structure or chemical structure pattern like SMILES. Simplified Molecular Input Line Entry System (SMILES) is a line notation for entering and representing molecule [8]. AMPA and $\mathrm{GABA}_{\mathrm{A}}$ receptors are mainly present in CNS. Thus, for targeting AMPA and $\mathrm{GABA}_{\mathrm{A}}$ receptors, the compound must cross the Blood Brain Barrier. All the analogues were screened for their BBB permeability using online tool $\mathrm{BBB}$ Predictor [9] 
(http://cbligand.org/cbid/BBB predictor.ph

p). The tool uses SVM algorithm for BBB permeability prediction.

\section{Docking}

Docking was done for all $\mathrm{BBB}$ positive analogues of Gossypin, Gossypin itself and 4 standard drugs against 4COF receptor. Four standard drugs chosen for docking studies are Phenacemide (inhibitor of Sodium channel protein type- 1 subunit- $\alpha$ ), Lamotrigine (inhibitor of Sodium channel protein type- 2 subunit- $\alpha$ ), Methyphenobarbital (potentiator of $\mathrm{GABA}_{\mathrm{A}}$ receptor subunit $\alpha-1, \alpha-2, \alpha-3, \alpha-4$, $\alpha-5$ and $\alpha-6$ ) and Clobazam (positive allosteric modulator of $\mathrm{GABA}_{\mathrm{A}}$ receptor). The software used to perform docking is Hex v8.0 [10].

\section{RESULTS AND DISCUSSION}

\section{Screening of gossypin analogues}

PubChem database was used to screen the analogues of gossypin. According to the selected screening parameters all the analogue structures were $\geq 90 \%$ similar to gossypin structure and their molecular weight was in range of $450-500 \mathrm{~g} / \mathrm{mol}$. This produced the list of 2683 analogues of gossypin. The top and best 20 analogues were selected for further study (Supplementary table 1).

\section{Property prediction}

Compounds used as medicines for humans usually follow Lipinski rule of five [11]. If a compound does not follow the Lipinski's rule, then it means that the compound has poor properties and needs to be modified according to the pharmacokinetic and pharmacodynamics requirements. For example, number of violations (nviolation) should be zero for any compound to have good absorption and permeability. It was observed that nineanalogues (analogue 7, 8, $9,10,11,12,13,14,15)$ out of 20 analogues have zero number of violations. Interestingly, gossypin itself have two numbers of violations (Table 2).

\section{Bioactivity Prediction}

The gossypin and its 20 analogues were submitted to online software Molinspiration for prediction of their bioactivity in 5 different virtual assays like GPCR ligand, Ion channel modulator, Kinase inhibitor, Protease inhibitor and Enzyme inhibitor (Table 3).

It was observed that gossypin analogues were better than gossypin in signaling related functions as they scored well for GPCR ligand property. Also, the analogues were equally good as gossypin to be used as an enzyme inhibitor.

\section{Toxicity prediction}

The 20 analogues were also analysed for prediction of their toxicity in human system. All the analogues were observed to be fine and safe and therefore were chosen for further analysisas a drug (Table 4).

\section{Blood Brain Barrier (BBB) Permeability prediction}


In order to target AMPA receptor and $\mathrm{GABA}_{\mathrm{A}}$ receptor present in the CNS, the compound must cross the Blood Brain Barrier. BBB Prediction was done for gossypin, all 20 analogues of gossypinand 4 Standard drugs marketed for epilepsy (Phenacemide, Lamotrigine, Methyl phenobarbital, and Clobazam). The result of $\mathrm{BBB}$ prediction shows that 7 analogues (analog 1, 2, 3, 11, 12, 13, and 14), Gossypin, and all 4 Standard drugs are BBB positive according to both SVM algorithm and AdaBoost algorithm except for Gossypin which is BBB negative according to AdaBoost algorithm (Table 5).

\section{Docking}

HEXv8.0 was used for docking BBB positive analogues, Gossypin and 4
Standard drugs with AMPA receptor (3UA8) and $\mathrm{GABA}_{\mathrm{A}}$ receptor $(4 \mathrm{COF})$. It was observed that analogue 11 have minimum binding energy with $3 \mathrm{UA} 8$ and analogue 13 have minimum binding energy with $4 \mathrm{COF}$. The 4 standard drugs have the maximum binding energy with both receptors. Gossypin is at the $7^{\text {th }}$ position in both cases (Table 6).

The best binding analogue of Gossypin to AMPA receptor was observed to be Analog 11, 12 and 13 (Figure 1). Their binding energies were better than Gossypin and the marketed drugs (Table 6).

The best binding analogue of gossypin to GABA receptor was observed to be Analog 13, 11 and 3. Their binding energies were better than gossypin and the marketed drugs (Figure 2).

Table 2: Compounds property prediction

\begin{tabular}{|c|c|c|c|c|}
\hline S. No & Analogues & MiLogP & TPSA & nviolations \\
\hline $\mathbf{0}$ & Gossypin & -0.625 & 230.731 & 2 \\
\hline 1 & 90306440 & -1.441 & 217.591 & 2 \\
\hline 2 & 90064061 & 0.318 & 201.269 & 2 \\
\hline 3 & 90058541 & 0.318 & 201.269 & 2 \\
\hline 4 & 90021694 & -0.057 & 199.509 & 2 \\
\hline 5 & 90021289 & 0.171 & 199.509 & 2 \\
\hline 6 & 89909463 & 0.777 & 212.674 & 2 \\
\hline 7 & 89905265 & 1.99 & 120.357 & $\mathbf{0}$ \\
\hline 8 & 89894278 & 1.486 & 107.217 & 0 \\
\hline 9 & 89894237 & 2.329 & 131.351 & $\mathbf{0}$ \\
\hline 10 & 89894207 & 2.329 & 131.351 & $\mathbf{0}$ \\
\hline 11 & $\mathbf{8 9 8 8 8 4 7 7}$ & 2.081 & 144.153 & $\mathbf{0}$ \\
\hline 12 & 89869617 & 2.081 & 144.153 & $\mathbf{0}$ \\
\hline 13 & 89869564 & 2.081 & 144.153 & $\mathbf{0}$ \\
\hline 14 & 89843654 & 2.162 & 148.059 & $\mathbf{0}$ \\
\hline 15 & 89815091 & 1.935 & 96.223 & $\mathbf{0}$ \\
\hline 16 & 89718967 & -0.364 & 210.503 & 2 \\
\hline 17 & 89683120 & 0.269 & 199.509 & 2 \\
\hline 18 & 89654040 & -0.104 & 210.503 & 2 \\
\hline 19 & 89646653 & -0.179 & 216.58 & 2 \\
\hline 20 & 89398710 & 0.313 & 204.837 & 2 \\
\hline
\end{tabular}


Table 3: Bioactivity prediction of gossypin and its analogues

\begin{tabular}{|c|c|c|c|c|c|c|}
\hline S.No. & Analogues & $\begin{array}{c}\text { GPCR } \\
\text { ligand }\end{array}$ & $\begin{array}{c}\text { Ion channel } \\
\text { modulator }\end{array}$ & $\begin{array}{c}\text { Kinase } \\
\text { inhibitor }\end{array}$ & $\begin{array}{c}\text { Protease } \\
\text { inhibitor }\end{array}$ & $\begin{array}{c}\text { Enzyme } \\
\text { inhibitor }\end{array}$ \\
\hline $\mathbf{0}$ & Gossypin & $\mathbf{0 . 0 0}$ & $\mathbf{- 0 . 0 0}$ & $\mathbf{0 . 1 2}$ & $\mathbf{- 0 . 0 9}$ & $\mathbf{0 . 4 2}$ \\
\hline 1 & $\mathbf{9 0 3 0 6 4 4 0}$ & $\mathbf{0 . 1 3}$ & $\mathbf{0 . 0 5}$ & $\mathbf{- 0 . 0 3}$ & $\mathbf{0 . 1 1}$ & $\mathbf{0 . 4 3}$ \\
\hline 2 & $\mathbf{9 0 0 6 4 0 6 1}$ & $\mathbf{0 . 0 9}$ & $\mathbf{- 0 . 0 7}$ & $\mathbf{0 . 2 2}$ & $\mathbf{0 . 1 8}$ & $\mathbf{0 . 4 2}$ \\
\hline 3 & $\mathbf{9 0 0 5 8 5 4 1}$ & $\mathbf{0 . 0 9}$ & $\mathbf{- 0 . 0 7}$ & $\mathbf{0 . 2 2}$ & $\mathbf{0 . 1 8}$ & $\mathbf{0 . 4 2}$ \\
\hline 4 & $\mathbf{9 0 0 2 1 6 9 4}$ & $\mathbf{0 . 0 2}$ & $\mathbf{- 0 . 0 9}$ & $\mathbf{0 . 1 2}$ & $\mathbf{- 0 . 1 1}$ & $\mathbf{0 . 3 8}$ \\
\hline $\mathbf{5}$ & $\mathbf{9 0 0 2 1 2 8 9}$ & $\mathbf{0 . 0 1}$ & $\mathbf{- 0 . 1 0}$ & $\mathbf{0 . 0 9}$ & $\mathbf{- 0 . 1 0}$ & $\mathbf{0 . 3 7}$ \\
\hline $\mathbf{6}$ & $\mathbf{8 9 9 0 9 4 6 3}$ & $\mathbf{- 0 . 0 2}$ & $\mathbf{- 0 . 0 8}$ & $\mathbf{- 0 . 1 4}$ & $\mathbf{0 . 0 5}$ & $\mathbf{0 . 2 4}$ \\
\hline 7 & $\mathbf{8 9 9 0 5 2 6 5}$ & $\mathbf{- 0 . 1 0}$ & $\mathbf{- 0 . 2 6}$ & $\mathbf{0 . 2 5}$ & $\mathbf{- 0 . 3 0}$ & $\mathbf{0 . 2 2}$ \\
\hline 8 & $\mathbf{8 9 8 9 4 2 7 8}$ & $\mathbf{- 0 . 0 6}$ & $\mathbf{- 0 . 0 9}$ & $\mathbf{- 0 . 1 9}$ & $\mathbf{- 0 . 1 6}$ & $\mathbf{0 . 1 3}$ \\
\hline 9 & $\mathbf{8 9 8 9 4 2 3 7}$ & $\mathbf{- 0 . 1 6}$ & $\mathbf{- 0 . 2 8}$ & $\mathbf{0 . 2 8}$ & $\mathbf{- 0 . 3 2}$ & $\mathbf{0 . 3 0}$ \\
\hline 10 & $\mathbf{8 9 8 9 4 2 0 7}$ & $\mathbf{- 0 . 1 6}$ & $\mathbf{- 0 . 2 8}$ & $\mathbf{0 . 2 8}$ & $\mathbf{- 0 . 3 2}$ & $\mathbf{0 . 3 0}$ \\
\hline 11 & $\mathbf{8 9 8 8 8 4 7 7}$ & $\mathbf{0 . 0 1}$ & $\mathbf{- 0 . 1 2}$ & $\mathbf{- 0 . 0 4}$ & $\mathbf{- 0 . 0 1}$ & $\mathbf{0 . 1 7}$ \\
\hline 12 & $\mathbf{8 9 8 6 9 6 1 7}$ & $\mathbf{0 . 0 1}$ & $\mathbf{- 0 . 1 2}$ & $\mathbf{- 0 . 0 4}$ & $\mathbf{- 0 . 0 1}$ & $\mathbf{0 . 1 7}$ \\
\hline 13 & $\mathbf{8 9 8 6 9 5 6 4}$ & $\mathbf{0 . 0 1}$ & $\mathbf{- 0 . 1 2}$ & $\mathbf{- 0 . 0 4}$ & $\mathbf{- 0 . 0 1}$ & $\mathbf{0 . 1 7}$ \\
\hline 14 & $\mathbf{8 9 8 4 3 6 5 4}$ & $\mathbf{0 . 0 2}$ & $\mathbf{- 0 . 2 2}$ & $\mathbf{0 . 1 3}$ & $\mathbf{- 0 . 0 8}$ & $\mathbf{0 . 2 8}$ \\
\hline 15 & $\mathbf{8 9 8 1 5 0 9 1}$ & $\mathbf{0 . 0 4}$ & $\mathbf{- 0 . 2 6}$ & $\mathbf{- 0 . 2 0}$ & $\mathbf{- 0 . 1 3}$ & $\mathbf{0 . 1 6}$ \\
\hline 16 & $\mathbf{8 9 7 1 8 9 6 7}$ & $\mathbf{0 . 0 6}$ & $\mathbf{- 0 . 0 4}$ & $\mathbf{0 . 1 3}$ & $\mathbf{- 0 . 0 6}$ & $\mathbf{0 . 4 2}$ \\
\hline 17 & $\mathbf{8 9 6 8 3 1 2 0}$ & $\mathbf{0 . 1 1}$ & $\mathbf{- 0 . 0 7}$ & $\mathbf{0 . 1 5}$ & $\mathbf{- 0 . 0 6}$ & $\mathbf{0 . 5 4}$ \\
\hline 18 & $\mathbf{8 9 6 5 4 0 4 0}$ & $\mathbf{0 . 0 4}$ & $\mathbf{- 0 . 1 0}$ & $\mathbf{0 . 1 5}$ & $\mathbf{- 0 . 0 6}$ & $\mathbf{0 . 4 2}$ \\
\hline 19 & $\mathbf{8 9 6 4 6 6 5 3}$ & $\mathbf{0 . 0 4}$ & $\mathbf{- 0 . 1 1}$ & $\mathbf{- 0 . 0 2}$ & $\mathbf{- 0 . 0 1}$ & $\mathbf{0 . 3 8}$ \\
\hline 20 & $\mathbf{8 9 3 9 8 7 1 0}$ & $\mathbf{0 . 1 8}$ & $\mathbf{0 . 0 3}$ & $\mathbf{0 . 0 1}$ & $\mathbf{0 . 1 3}$ & $\mathbf{0 . 4 3}$ \\
\hline
\end{tabular}

Table 4: Toxicity prediction of gossypin and its analogues

\begin{tabular}{|c|c|c|}
\hline S.No. & Analogues & RESULT \\
\hline $\mathbf{0}$ & Gossypin & Substance would not be expected to be a safety concern \\
\hline 1 & 90306440 & Substance would not be expected to be a safety concern \\
\hline 2 & 90064061 & Substance would not be expected to be a safety concern \\
\hline 3 & 90058541 & Substance would not be expected to be a safety concern \\
\hline 4 & 90021694 & Substance would not be expected to be a safety concern \\
\hline 5 & 90021289 & Substance would not be expected to be a safety concern \\
\hline 6 & 89909463 & Substance would not be expected to be a safety concern \\
\hline 7 & 89905265 & Substance would not be expected to be a safety concern \\
\hline 8 & 89894278 & Substance would not be expected to be a safety concern \\
\hline 9 & 89894237 & Substance would not be expected to be a safety concern \\
\hline 10 & 89894207 & Substance would not be expected to be a safety concern \\
\hline 11 & $\mathbf{8 9 8 8 8 4 7 7}$ & Substance would not be expected to be a safety concern \\
\hline 12 & 89869617 & Substance would not be expected to be a safety concern \\
\hline 13 & 89869564 & Substance would not be expected to be a safety concern \\
\hline 14 & 89843654 & Substance would not be expected to be a safety concern \\
\hline 15 & 89815091 & Substance would not be expected to be a safety concern \\
\hline 16 & 89718967 & Substance would not be expected to be a safety concern \\
\hline 17 & 89683120 & Substance would not be expected to be asafety concern \\
\hline 18 & 89654040 & Substance would not be expected to be a safety concern \\
\hline 19 & 89646653 & Substance would not be expected to be a safety concern \\
\hline 20 & 89398710 & Substance would not be expected to be a safety concern \\
\hline
\end{tabular}

Table 5: Blood Brain Barrier Permeability prediction

\begin{tabular}{|c|c|c|c|}
\hline S.No. & ANALOGUES & \multicolumn{2}{|c|}{ Algorithm } \\
\cline { 3 - 4 } & & SVM & AdaBoost \\
\hline $\mathbf{0}$ & Gossypin & + & - \\
\hline $\mathbf{2}$ & $\mathbf{9 0 3 0 6 4 4 0}$ & + & + \\
\hline $\mathbf{3}$ & $\mathbf{9 0 0 6 4 0 6 1}$ & + & + \\
\hline $\mathbf{4}$ & $\mathbf{9 0 0 5 8 5 4 1}$ & + & - \\
\hline $\mathbf{5}$ & $\mathbf{9 0 0 2 1 6 9 4}$ & - & - \\
\hline $\mathbf{6}$ & $\mathbf{9 0 0 2 1 2 8 9}$ & - & - \\
\hline
\end{tabular}




\begin{tabular}{|c|c|c|c|}
\hline $\mathbf{7}$ & $\mathbf{8 9 9 0 5 2 6 5}$ & - & + \\
\hline $\mathbf{8}$ & $\mathbf{8 9 8 9 4 2 7 8}$ & - & - \\
\hline $\mathbf{8}$ & $\mathbf{8 9 8 9 4 2 3 7}$ & - & + \\
\hline 10 & $\mathbf{8 9 8 9 4 2 0 7}$ & - & + \\
\hline 11 & $\mathbf{8 9 8 8 8 4 7 7}$ & + & + \\
\hline 12 & $\mathbf{8 9 8 6 9 6 1 7}$ & + & + \\
\hline 13 & $\mathbf{8 9 8 6 9 5 6 4}$ & + & + \\
\hline 14 & $\mathbf{8 9 8 4 3 6 5 4}$ & + & + \\
\hline 15 & $\mathbf{8 9 8 1 5 0 9 1}$ & - & + \\
\hline 16 & $\mathbf{8 9 7 1 8 9 6 7}$ & - & - \\
\hline 17 & $\mathbf{8 9 6 8 3 1 2 0}$ & - & - \\
\hline 18 & $\mathbf{8 9 6 5 4 0 4 0}$ & - & - \\
\hline 19 & $\mathbf{8 9 6 4 6 6 5 3}$ & - & + \\
\hline 20 & $\mathbf{8 9 3 9 8 7 1 0}$ & + & + \\
\hline 21 & Phenacemide & + & + \\
\hline 22 & Lamotrigine & + & + \\
\hline 24 & Methylphenobarbital & + & + \\
\hline
\end{tabular}

Table 6: Docking energies of BBBpositive analogues, gossypin and 4 standard drugs with 3AU8 and 4COF receptors

\begin{tabular}{|c|c|c|c|}
\hline Receptor: 3AU8 & \multicolumn{3}{|c|}{ Receptor: 4COF } \\
\hline Ligand & Energy & Ligand & Energy \\
\hline 3UA8:Analog 11 & -330.56 & 4COF:Analog 13 & -414.76 \\
\hline 3UA8:Analog 12 & -319.39 & 4COF:Analog 11 & -392.93 \\
\hline 3UA8:Analog 13 & -317.63 & 4COF:Analog 3 & -376.66 \\
\hline 3UA8:Analog 2 & -305.49 & 4COF:Analog 2 & -364.75 \\
\hline 3UA8:Analog 14 & -304.54 & 4COF:Analog 14 & $-\mathbf{3 6 1 . 8 2}$ \\
\hline 3UA8:Analog 3 & -297.09 & 4COF:Analog 12 & -353.28 \\
\hline 3UA8:Gossypin & -291.89 & 4COF:Gossypin & -341.91 \\
\hline 3UA8:Analog 1 & -267.84 & 4COF:Analog 1 & -320.88 \\
\hline 3UA8:Clobazam & -265.55 & 4COF:Clobazam & -214.67 \\
\hline 3UA8:Lamotrigine & -213.92 & 4COF:Methylphenobarbital & -189.91 \\
\hline 3UA8:Methylphenobarbital & -196.53 & 4COF:Lamotrigine & -188.91 \\
\hline 3UA8:Phenacemide & -172.63 & 4COF:Phenacemide & -167.89 \\
\hline
\end{tabular}
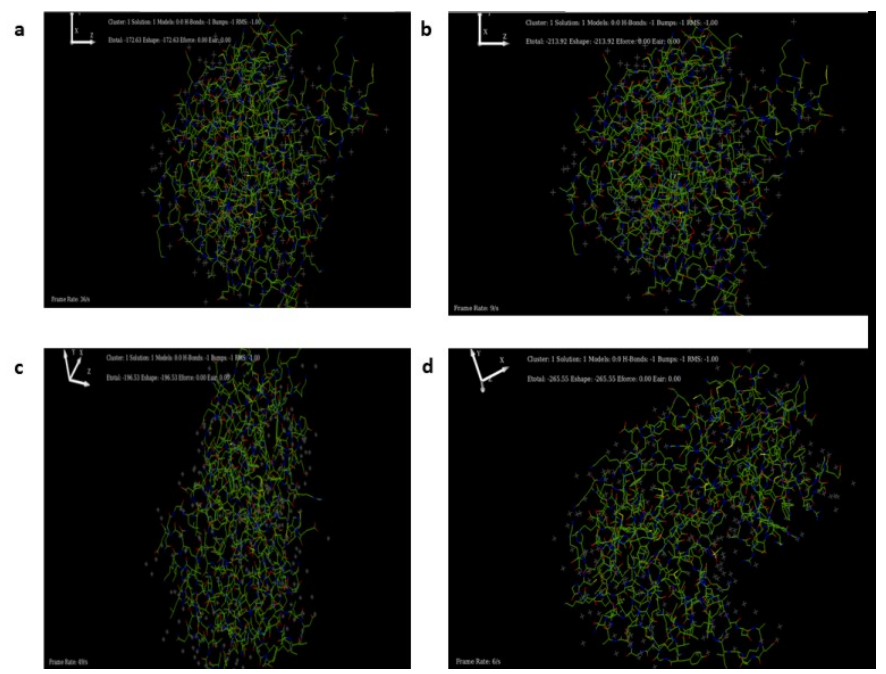

Figure 1: Docking of gossypin and its best analogues with AMPA Receptor (3UA8)(a) gossypin with 3 UA8 (b) Analogue 11 with $3 \mathrm{UA8}$ (c) Analogue 12 with $3 \mathrm{UA8}$ (d) Analogue 13 with 3 UA8 

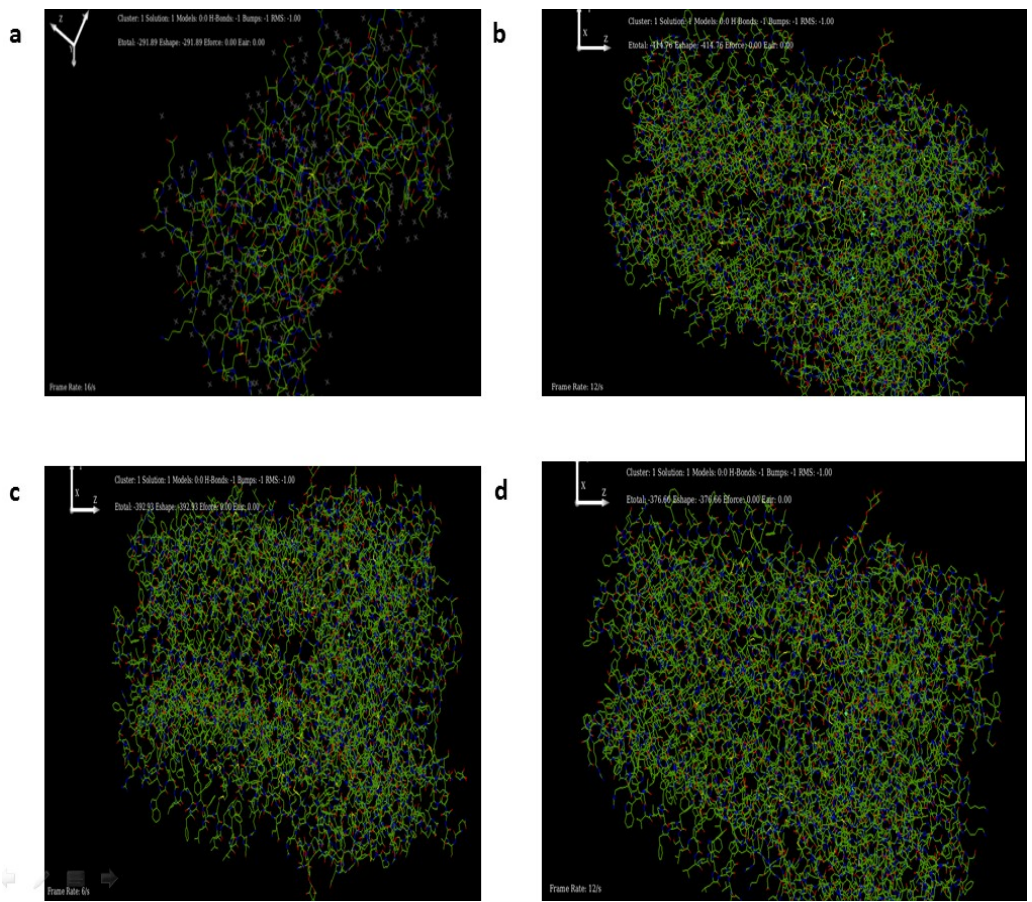

Figure 2: Docking of Gossypin and its best analogues with GABA Receptor (4COF).Gossypin with 4COF (b) Analog 13 with 4 COF (c) Analog 11 with 4 COF (d) Analog 3 with 4COF

\section{CONCLUSION}

The computational analysis of gossypin and its structural analogues revealed that gossypin and its analogues can be a better binding analog to AMPA and GABA receptors than the already marketed drugs for epilepsy. The best analogues are also predicted to be able to cross blood brain barrier. These analogues can be analysed further for their specificity to other bioassays.

Epilepsy drugs are prescribed to control seizures, and rarely surgery is necessary if medications are ineffective. The main cause of seizures in epilepsy is oxidative stress, inflammation and failure of neural circuitry. Oxidative stress, defined as a disturbance in the balance between the production of reactive oxygen species (free radicals) and antioxidant defences, is discussed in relation to its possible role in the production of tissue damage in diabetes mellitus. Important free radicals are described and biological sources of origin discussed, together with the major antioxidant defence mechanisms. Examples of the possible consequences of free radical damage are provided with special emphasis on lipid peroxidation. Since Gossypin is an antioxidant, further analysis remains to calculate the potential of these analogues as antioxidant.

The inadequate therapeutic options and extensive side effects of the current drugs challenges in the efficacy and bioavailability of the natural drugs. This has posed an urgent need to develop more effective herbal compounds as well as their analogues for the therapeutic action as well as side effect reduction. The docking 
analysis has two main goals; one is the accurate structural modelling and second one is accurate prediction and identification of molecular \& structural features which are responsible for biological activity of ligand. The specific biological activity or the forecast of compound modifications which leads to improve the potency. The potential lead molecule/s of gossypin analogues obtained from the molecular docking in the current study can be further evaluated in vitro and in vivo cell line and animal models. The present study shows screening of 20 different analogues of gossypin to cross blood brain barrier. Various docking studies were performed on GABAA and AMPA receptors with gossypin analogues along with gossypin and 4 FDA approved anti-epileptic drugs showed better efficacy in terms of $\mathrm{BBB}$ crossing and their docking studies were better than the approved anti-epileptic drug. These analogues can be used for future drug development after preclinical studies. Since Gossypin is an antioxidant, further analysis remains to calculate the potential of these analogues as antioxidant.

\section{ACKNOWLEDGEMENT}

We would like to acknowledge Dr. Ashok K. Chauhan, Founder President, Amity University Uttar Pradesh, Noida for providing the infrastructure and support.

\section{REFERENCES}

[1] Anand P, Kunnumakkara AB, Newman $\mathrm{R}$ and BBA. Bioavailability of Quercetin: Problems and Promises, Curr Med Chem, 220, 2013, 2572-82.

[2] Rasilingam D, Duraisamy S, Subramanian R. Anticonvulsant activity of bioflavonoid gossypin, Bangladesh J Pharmacol, 4, 2009, $51-4$.

[3] Chandrashekhar VM, Ganapaty S, Ramkishan A, Narsu ML. Neuroprotective activity of gossypin from Hibiscus vitifolius against global cerebral ischemia model in rats. Indian J Pharmacol, 45, 2013, 575-80.

[4] Behl C, Davis JB, Lesley R, Schubert D. Hydrogen peroxide mediates amyloid $\beta$ protein toxicity. Cell, 77, 1994, 817-27.

[5] Yoon I, Kwang HL, Cho J. Gossypin protects primary cultured rat cortical cells from oxidative stress- and $\beta$-amyloid-induced toxicity. Arch Pharm Res,27, 2004, 454-9.

[6] Nagpal D, Agarwal N, Katare D. Evaluation of liposomal gossypin in animal models of epilepsy. Int $\mathrm{J}$ Pharm Pharm Sci, 8, 2014, 247-51.

[7] Kim S, Thiessen PA, Bolton EE, Chen J, Fu G, Gindulyte A, et al. 
PubChem substance and compound databases. Nucleic Acids Res, 44, 2016, 1202-13.

[8] Weininger D. J, SMILES, a Chemical Language and Information System. 1. Introduction to Methodology and Encoding Rule, Chem. Inj Comput. J Chem Inf Comput Sci, 28, 1988, 31-6.

[9] Liu H, Wang L, Lv M, Pei R, Li P, Pei Z, et al. AlzPlatform: An Alzheimer's disease domainspecific chemogenomics knowledgebase for polypharmacology and target identification research. J Chem Inf Model, 54, 2014, 1050-60.

[10] Thangavelu R, Harika M, Kumar T, Siva Sankar Reddy L. Docking studies of benzimidazole derivatives using hex 8.0 Synthesis and Microbial Evaluation of Amino Acid Anti Metabolites View project Anti cancer agents ,Int J Pharm Sci Res, 8, 2017, 1677-88.

[11] Lipinski CA, Lead- and drug-like compounds: The rule-of-five revolution. Drug Discov Today Technol,1, 2004, 337-41. 